\title{
«Casas» en las sociedades aymaras norpotosinas bajo dominio colonial: una reflexión sobre el modelo segmentario andino. El repartimiento de Macha (Audiencia de Charcas), 1613-1619
}

\author{
Carolina JURADO ${ }^{1}$ \\ Instituto de Historia Argentina y Americana «Dr. E. Ravignani» \\ CONICET - Universidad de Buenos Aires \\ jurado_carolina@yahoo.com.ar
}

Recibido: 29/6/2015

Aceptado: $12 / 5 / 2016$

\section{RESUMEN}

La presencia de agrupaciones sociales o «casas» que, regidas por el parentesco, integran el modelo segmentario de las sociedades aymaras prehispánicas y coloniales, logró un sólido consenso en la historiografía andina. A partir de un análisis histórico contextual de documentación colonial editada e inédita de repartimiento de Macha, y apelando al modelo de «sociétés à maisons» del antropólogo Claude Lévi-Strauss, el presente artículo aspira a complejizar la mirada sobre las casas aymaras, en tanto agrupaciones sociales heterogéneas que se sirven de, y al mismo tiempo, subvierten el lenguaje del parentesco en vistas a proteger sus intereses políticos en un contexto colonial cambiante.

Palabras clave: Aymaras, sociedad de casas, Lévi-Strauss, Charcas.

$$
\begin{gathered}
\text { «Houses» in Aymara Societies of North Potosi under Colonial Rule: } \\
\text { Revisiting the Andean Segmentary Model. Repartimiento of Macha } \\
\text { (Audiencia of Charcas), 1613-1619 }
\end{gathered}
$$

\begin{abstract}
The presence of kingshiped social groups or «houses», into the segmentary model of pre-Hispanic and colonial Aymara societies, achieved a solid consensus in the Andean historiography. From a contextual historical analysis of published and unpublished Macha colonial documentation, and appealing to the model of «sociétés à maisons» of Claude Lévi-Strauss, this article aims to enrich the analysis of Aymara houses as heterogeneous social groups that use and at the same time subvert the language of kinship in order to protect their political interests in a changing colonial context.
\end{abstract}

Key words: Aymara, house society, Lévi-Strauss, Charcas.

Sumario: 1. Introducción. 2. El rol de las casas en el modelo segmentario aymara. 3. Revisando la evidencia empírica. 4. Releyendo las casas del repartimiento de Macha. 5. Conclusiones. 6. Referencias documentales. 7. Referencias bibliográficas.

\section{Introducción}

Desde las primeras propuestas realizadas en 1987, la presencia de segmentos sociales o «casas» en las sociedades aymaras prehispánicas y coloniales logró un sólido

\footnotetext{
${ }^{1}$ Este trabajo se realizó en el marco de los proyectos PICT FONCyT 2012-2661 y UBACyT 20020120300052 y contiene parte de la tesis doctoral presentada en la Universidad de Buenos Aires (Argentina). Quisiera expresar mi agradecimiento a la Dra. Ana M. Presta y al Dr. Pablo Sendón por sus observaciones en esa oportunidad y a la Dra. Laura Quiroga por sus sugerencias a versiones previas del presente trabajo. Mi agradecimiento se extiende asimismo a los evaluadores de Revista Española de Antropología Americana.
} 
consenso en la etnohistoria, la etnografía y la arqueología andinas (Nielsen 2006: 67; Platt 1987: 376-377, 2009: 53; Platt et al. 2006: 663-666; Yapita y Arnold 1988: 209). El modelo, surgido del interés por clarificar la organización segmentaria de las sociedades aymaras, proponía la existencia de casas, consideradas grupos parentales, en las sociedades aymaras norpotosinas del período colonial. La propuesta tomaba como evidencia empírica documentación de inicios del siglo XVII, proveniente del repartimiento de Macha, jurisdicción administrativa-laboral colonial ubicada al norte del centro minero de Potosí (en el distrito de Charcas). Tanto en la Información de filiación como en el pleito por acceso al liderazgo analizados, los peticionarios indígenas, mediante los servicios de un escribano peninsular, sostenían pertenecer a distintas casas como argumento jurídico de estatus, en vistas a lograr la exención tributaria y/o el acceso al liderazgo indígena en el complejo decenio de 1610-1620. Asimiladas a ««familias» señoriales», las casas se delinearon en el modelo como grupos de descendencia duales y jerarquizados, parte constitutiva de un esquema segmentario aymara que las incluía al interior de pachaqas o centenas, ayllus menores y, finalmente, sayas o mitades (Platt 1987: 376).

En definiciones posteriores, el parentesco siguió conservando un lugar central al definirse la casa como un "grupo familiar y a sus descendientes», distinguiendo entre casas mayores y casas segundas, pues «las primeras representan la línea del mayorazgo y las segundas las líneas de los hijos menores» (Platt et al. 2006: 663). Incluso, más recientemente, se sugirió que las casas mencionadas en la documentación colonial serían los antecedentes de los grupos territoriales denominados «cabildos», que conformaban los ayllus menores o churi ayllus de algunas sociedades norpotosinas de fines del siglo XX (Platt 2009: 53).

En los últimos años, se propuso una lectura alternativa de la documentación colonial que sustenta el modelo segmentario, reinsertando los procesos judiciales y a sus actores sociales en el contexto histórico regional y virreinal al que pertenecían. Así, no sólo se resaltaron diferencias interpretativas en la lectura de la evidencia empírica sino que se puso en duda la existencia de pachaqas al interior de los ayllus del repartimiento de Macha de los siglos XVI y XVII. Junto a ello, el análisis demográfico y estadístico de padrones de indios o censos poblacionales inéditos del mismo repartimiento -y contemporáneos a los expedientes judiciales mencionados-, en los cuales los oficiales reales clasificaban a ciertos integrantes del repartimiento de Macha en casas, complejizó el concepto y su significación para su mitad superior o Hanansaya (Jurado 2010, 2013). En ese sentido, se destacó que, en dicha documentación, el término casa constituía un concepto usado por el juez revisitador y/o su escribano para describir distintas prácticas sociales que observaba al interior de algunos segmentos o ayllus del repartimiento de Macha en torno a 1619.

Continuando esta línea de trabajo, el propósito del presente artículo es enriquecer el análisis de las casas en las sociedades aymaras bajo el primer siglo de dominio colonial, volviendo a considerar el principal caso de estudio propuesto por la historiografía: el repartimiento de Macha, en la región norpotosina. Sin embargo, más que interrogarse por esquemas segmentarios generalizables, la perspectiva adoptada propone una mirada histórica contextual de la documentación colonial editada e inédita mencionadas, que rescate las estrategias e intereses de los actores sociales 
en un contexto colonial cambiante. Para ello, a continuación, se examinan de modo sintético las principales características atribuidas a las casas en el modelo segmentario andino, junto al marco historiográfico en el que se gestó. Luego, se analiza la evidencia empírica del caso Macha a partir de una mirada integradora que ponga en diálogo los diferentes tipos de documentación colonial conocida hasta el momento en los que actores sociales diversos se sirvieron del concepto de casa. Una mirada conjunta, sumada al análisis del uso dado al término casa en padrones de indios de la mitad Hurinsaya del repartimiento de Macha, hasta el momento inéditos, indica que el término encapsulaba prácticas sociales heterogéneas que trascendían el parentesco como único criterio de pertenencia. En ese sentido, finalmente, el trabajo apela al modelo de sociétés à maisons, introducido por el antropólogo Claude LéviStrauss, y cuyas potencialidades para el análisis de diversas sociedades indígenas prehispánicas y coloniales ha demostrado la historiografía mesoamericanista, como una clave de lectura que posibilite pensar en agrupaciones sociales que se sirven de, y al mismo tiempo, subvierten el lenguaje del parentesco en vistas a proteger sus intereses políticos y económicos. Sin embargo, el análisis contextual de la documentación colonial sugiere que el repartimiento de Macha guarda importantes diferencias con la propuesta «levistraussiana», al asumir las casas de Macha, en tanto entidades sociales, políticas y económicas duales y jerarquizadas, no tanto un rol de guardianas de derechos territoriales y otras posesiones materiales sino, sobre todo, un rol central en la provisión y el control de los cargos de la jerarquía de liderazgo indígena de repartimiento, tal como se evidenciaba desde fines del siglo XVI.

\section{El rol de las casas en el modelo segmentario aymara}

Existe consenso al sostener que la mayoría de las sociedades prehispánicas quechua y aymara hablantes de las tierras altas de las actuales repúblicas de Bolivia y Perú se organizaban de manera segmentaria (Harris 1986; Murra 1975; Nielsen 2007; Platt 1987; Platt et al. 2006; Rasnake 1989; entre otros), sin por ello perder sus elementos centralizados y jerárquicos (Nielsen 2006: 67; Stern 1982: 32-39). En la base de estas sociedades, las unidades domésticas se incluían, en un nivel mínimo, en ayllus o grupos de descendientes de un antepasado común, que administraban de modo colectivo recursos estratégicos para su supervivencia. A su vez, los ayllus integraban niveles organizativos crecientemente englobantes, dentro de mitades, ayllus mayores, federaciones y confederaciones, sin que los distintos segmentos perdieran su identidad ni cierto grado de autonomía.

Este principio segmentario, aplicado a las poblaciones aymaras, se analizó en detalle para el caso concreto del segmento Macha, integrante de la prehispánica Federación Qaraqara (Platt 1987). Como se observa en la Figura 1, el modelo planteaba que el grupo identificado con ese nombre se dividía en dos grandes mitades o sayas, Aransaya y Urinsaya, o «los de arriba» y «los de abajo», subdivididas a su vez, cada una de ellas, en cinco ayllus menores. Finalmente, en el interior de estos se incluían grupos más pequeños, las centenas o pachaqas, que conformaban la mínima unidad tributaria por encima de la unidad doméstica. Es a este nivel segmentario que se deli- 


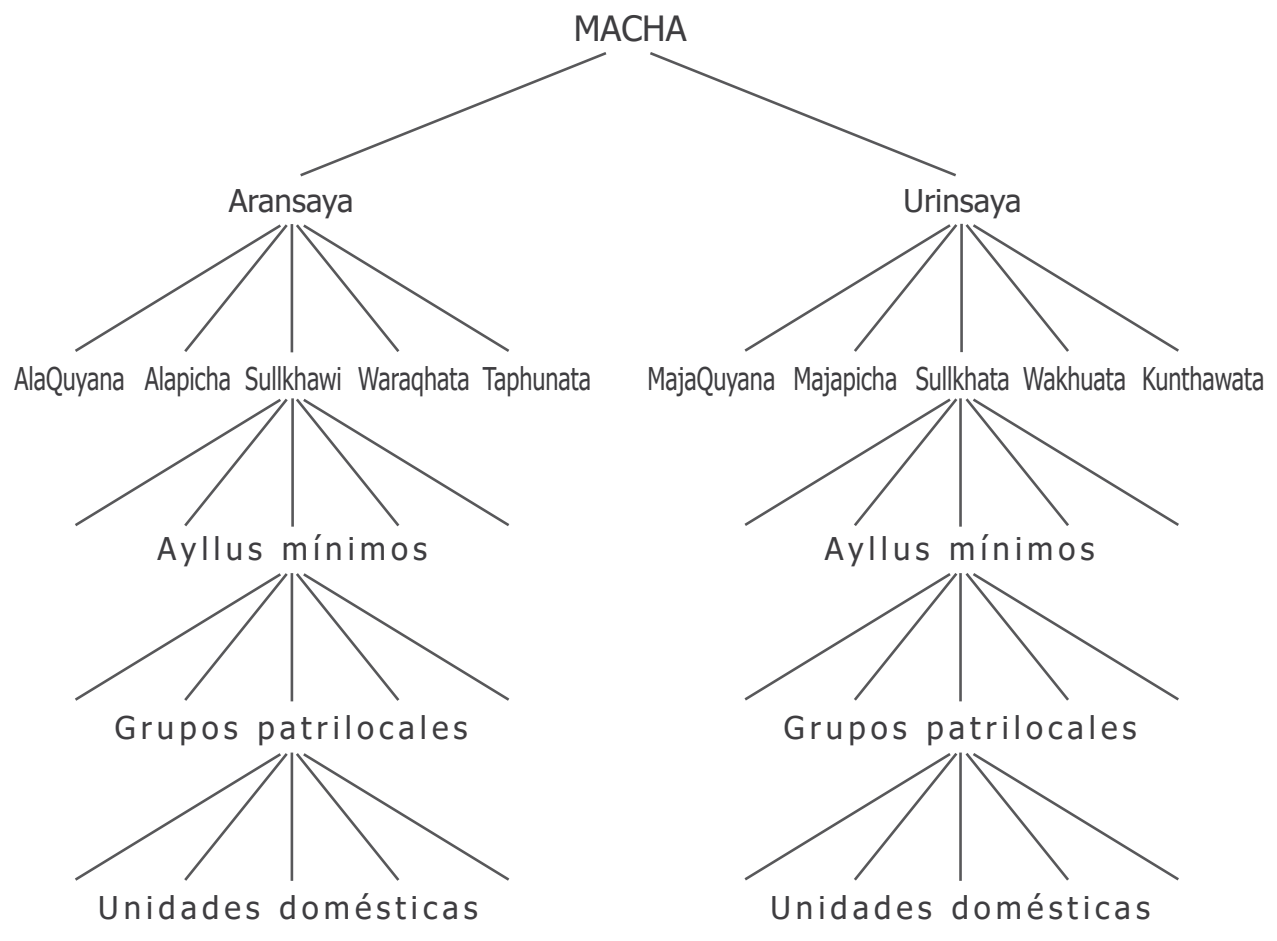

Figura 1: Estructura segmentaria en Macha (según Platt 1978: 1083, fig. 2).

neaban las casas, entendidas como grandes «familias» que, en una marcada dualidad, proveían el liderazgo: la «casa principal» brindaba los líderes de pachaqas -uno de los cuales gobernaba todo el ayllu menor-, mientras que de la «casa segunda» surgía su compañero, asimilado al nombre colonial de segunda persona.

El sustento empírico de la presencia de casas que regían el gobierno de los segmentos mínimos o pachaqas provenía de una Información de Filiación y de un pleito por liderazgo de indígenas del repartimiento de Macha de inicios del siglo XVII. Como se mencionó más arriba, en ellos los peticionarios, mediante un escribano peninsular, afirmaban pertenecer a casas, presentes en dos de los cinco ayllus menores que conformaban la mitad Hanansaya del repartimiento ${ }^{2}$. Sus declaraciones permitían hipotetizar acerca de un consejo de señores indígenas, representantes de las pachaqas de cada ayllu menor, que nombraba al jilaqata o líder del ayllu; principio electivo que, a su vez y según proponía el modelo, se replicaba al elegir al líder de la mitad o saya. Este trabajo inicial se interrogaba sobre los márgenes de autonomía y capacidad de presión de los segmentos y sus líderes sobre las instancias políticas superiores del

2 Las informaciones de filiación consistían en documentos legales probatorios, similares a las probanzas de méritos y servicios, aunque con interrogatorios y testimonios más acotados en extensión, tendientes a demostrar genealogías convenientes a lo solicitado. Un análisis interpretativo de la documentación mencionada se encuentra en Jurado 2013. 
repartimiento de Macha, argumento que, en última instancia, se fundaba en la existencia de casas jerarquizadas, proveedoras de líderes que acordaban el gobierno en los respectivos niveles segmentarios.

La propuesta anterior se enmarcó en una tendencia disciplinaria de la historiografía andina que desde fines de la década de 1960 delineó las trayectorias parentales, políticas y socio-económicas de algunos grandes mallku o líderes aymaras del período colonial (Choque 1978, 1983; Espinoza 1969, 1981; Murra 1978; Rivera 1978; Rivera y Platt 1978; Saignes y Loza 1984), confirmando la existencia de una sociedad andina jerarquizada y socialmente estratificada (Rostworowski 1977; Salomon 1975; Spalding 1974). La renovación historiográfica propugnaba la lectura de documentación proveniente de la administración de justicia, como testamentos y probanzas de méritos y servicios de líderes indígenas junto con memoriales y correspondencia diversa, como vía principal para evaluar la figura cacical en relación con el dominio colonial y con su enriquecimiento a partir de la participación en los circuitos mercantiles regionales, sumado al análisis de problemas de sucesión y legitimidad cacicales. A la luz del discurso de los capitanes de mita don Juan Colque Guarache, Pedro Chipana, Bartolomé Qhari, o Gabriel Fernández Guarachi, la historiografía confirmó que las autoridades aymaras coloniales lo eran no sólo por combinar su rol de activos comerciantes, garantes de la recaudación tributaria y la movilización de la mano de obra de sus indígenas en beneficio del poder colonial, sino por constituir elementos necesarios para la continuidad de su comunidad, asumiendo su pertenencia a prestigiosos linajes prehispánicos. Así, el Interrogatorio de la primera Probanza de méritos y servicios de don Juan Colque Guarache [1575], capitán general de los mitayos quillacas y asanaques, preguntaba «Si saben, etc. que el dicho Guarache fue (...) del ayllo Malcoca, que en lengua española quiere decir generacion de señores y fue de la casa de Guarache» (Espinoza 1981: 239; el subrayado es nuestro).

A la luz de las probanzas de méritos y servicios, los investigadores se abocaron a reconstruir las genealogías cacicales conservadas mediante la estrategia jurídicodiscursiva de líderes indígenas que peticionaron por su acceso al cargo u otros beneficios. Posteriores a la reorganización que el Virrey don Francisco de Toledo efectuara del gobierno indígena en la década de 1570, esta documentación demostraba, en todos los casos, que los peticionarios descendían -en términos de parentesco- de un «tronco» (Espinoza 1981: 198) de valientes líderes preincaicos, cuyo estatus acrecentado por la dominación incaica trascendía a la época colonial en honrosos servicios al Rey. Es importante señalar que esta lectura de las probanzas de méritos y servicios indígenas privilegió el contenido que «revelaban» del pasado prehispánico de los segmentos que los líderes andino coloniales sostenían haber gobernado, antes que el análisis del contexto histórico de producción del escrito legal que, en sí mismas, constituían (Jurado 2014). En ese sentido, las probanzas de méritos y servicios eran un tipo de documento ligado a la administración de justicia, que, con fines persuasivos, narraba méritos del peticionario y de sus antepasados en vistas a solicitar a la Corona recompensas materiales y simbólicas por sus honras y servicios (Jurado 2014; Macleod 1998). Para el líder indígena, o aquel que aspirara a serlo, las probanzas de méritos y servicios se volvieron necesarias para obtener sustento judicial en el acceso y sucesión en el cacicazgo si lograban probar los lazos genealógicos del peticionario 
con antiguos gobernantes locales. Desde 1603, la legislación regia había establecido la obligación de respetar la «costumbre» de sucesión hereditaria en los cacicazgos andinos; decisión ratificada por la Real Cédula del 19 de julio de 1614 (Díaz 1977: 49). Ambos decretos ordenaban a las audiencias resolver los pleitos sucesorios indígenas, conservando los derechos de los «caciques o principales descendientes de los primeros» (Recopilación de Leyes de Indias, Libro VI, Título VII, Ley Primera). De este modo, acorde a la legislación y a los manuales notariales hispanos, en las probanzas de méritos y servicios indígenas el linaje se postulaba como una estructura de parentesco central en la articulación de la herencia y la descendencia de la élite indígena gobernante. Dado que el corpus legal regio fomentaba los lazos biológicos como criterio de sucesión en el gobierno de los indígenas, toda documentación legal probatoria presentada para acceder al cargo de liderazgo debía ajustar su discurso en torno a la existencia y pertenencia del interesado a grupos de parientes privilegiados y jerárquicamente distinguidos, capaces de gobernar a los indígenas.

Fue en este aspecto parental que reparó la historiografía. Así, la publicación de los capítulos presentados al rey en 1582 por líderes aymaras -conocido como Memorial de Charcas-permitió a los investigadores confirmar «el poderoso espíritu señorial en el que se desenvolvieron y vivieron la integridad de los curacas peruanos de los siglos XVI y XVII» (Espinoza 1969: 117). Entre reclamos y demandas, los mallku firmantes expresaban su estatus -y el de sus antepasados-, demandando al Rey que

los hijos, nietos y hermanos de los caciques principales y señores que fueron antes de los ingas y despues de ellos, sean reservados de tasa y de los pechos a causa de que no lo han tenido por costumbre sino antes han sido reservados de otros como cavalleros e hijosdalgo (Espinoza 1969: 132-133).

Tal evocación discursiva de un linaje conformado por parientes lineales y colaterales como sostén de cada uno de los caciques principales en época colonial -pero que decía hundir sus raíces en tiempos preincaicos- coincidía con el discurso vertido en la documentación detallada anteriormente, al contar con similares objetivos jurídicolegales. Así, la reiteración del lenguaje genealógico y la homologación de su estatus al de los hidalgos castellanos conformaron el marco (conceptual) central para comprender el accionar de los líderes aymaras coloniales (Choque 1983; Espinoza 1981).

En este contexto historiográfico, la existencia de «grandes «familias»"», "«familias» señoriales» o casas que utilizaban el parentesco como criterio central de pertenencia y ordenamiento de los miembros de las sociedades segmentarias aymaras (Platt 1987: 376) fue bien recibida. Un año más tarde, en 1988, la propuesta se afirmó, al vincularse con el término aymara uta, concepto que designaba la construcción física del recinto habitacional aymara, la familia extendida que residía en él, hasta constituir la matriz de un grupo de descendientes. Basándose en la evidencia empírica anterior, la casa (uta) se definía como base de la autoridad en el período colonial, al ser no sólo la «fuente de la línea de descendencia sino también (...) fuente de la línea de autoridad del ayllu» (Yapita y Arnold 1988: 209).

Casi veinte años más tarde, el concepto de casa volvió a enfatizar su carácter parental en el análisis historiográfico. Enmarcada en el estudio de las «estirpes señoriales», se argumentó que la casa no sólo refería al «lugar de residencia del heredero mayor de un linaje [indígena]» sino que, en su acepción social, refería al «grupo familiar 
y a sus descendientes». Se distinguieron nuevamente las casas mayores de las casas segundas, pues «las primeras representan la línea del mayorazgo y las segundas las líneas de los hijos menores» (Platt et al. 2006: 663). Cual linajes, se propuso que las casas reconocían un antepasado común que, en el análisis, se asimiló a los vocablos aymaras achachi (ancestro) o tunu (tronco de la familia). Siguiendo las hipótesis, la segunda casa estaría formada por la descendencia de un hermano del líder de la casa principal, correspondiendo a la casa de los líderes indígenas segundas personas, cuya autoridad -se proponía- se ejercía en ausencia de los señores principales de la casa mayor. La probanza de méritos y servicios del cacique gobernador don Fernando Ayra de Arriutu [1638] -con su reclamo de pertenencia a casas por vía materna y paterna-, junto con los procesos judiciales de aspirantes a líderes del repartimiento de Macha, ya mencionados, constituyeron el sustento empírico de las propuestas detalladas. Descendencia, sucesión, jerarquía, duplicación, linaje de líderes indígenas a distinto nivel segmentario: todas estas características volvieron a vincularse a las casas, convertidas en elementos centrales en la organización socio-política de las sociedades aymaras desde tiempos prehispánicos (Platt et al. 2006: 663-665).

Finalmente, en 2009, y a partir del trabajo etnográfico realizado entre la población Macha en la década de 1970, la historiografía sostuvo que las casas mencionadas en la documentación colonial ya analizada constituían el antecedente de los cabildos -grupos territoriales o ayllus mínimos- que conformaban los ayllus menores o churi ayllus del siglo XX. Así, la Información de Filiación y el pleito por liderazgo indígena del repartimiento de Macha de inicios del siglo XVII volvían a proponerse como principal sostén empírico de la presencia en cada ayllu prehispánico de $p a-$ chaqas, con su mallki o momia ancestral y sus lugares de origen sagrados. Dado que cada ayllu menor y, en su interior, cada ayllu mínimo (o cabildo) de la sociedad Macha de la década de 1970 se conformaba de patrilinajes interconectados parentalmente, descendientes de un ancestro o pareja apical, se propuso que estos segmentos se encontraban en la documentación colonial con el nombre de «troncos de casas». En otros términos, pequeños grupos de descendencia interconectados parentalmente, conformados por las pachaqas reconocidas por el Inca Huayna Capac, habían sido los antepasados de los cabildos o ayllus mínimos de la organización social contemporánea (Platt 2009: 53).

\section{Revisando la evidencia empírica: sayas, ayllus y casas en el repartimiento de Macha del siglo XVII}

Como se mencionó más arriba, el sustento empírico para la comprensión de las casas dentro del modelo segmentario aymara provino principalmente de documentación judicial del repartimiento de Macha de inicios del siglo XVII. Para entonces, el repartimiento de Macha constituía una jurisdicción política-territorial-tributaria, ubicada 30 leguas al norte de la Villa Imperial de Potosí (en el distrito de Charcas). Sus tierras descendían desde la puna, bordeada por la actual Cordillera de los Azanaques, en torno al pueblo de reducción de San Pedro de Macha, y se extendían en sentido SO-NE hacia los valles del río Grande, en torno al pueblo de San Marcos de Miraflores, en el corazón 
del corregimiento de Chayanta. Según los padrones de indios inéditos consultados, sus aproximadamente 4.000 integrantes conformaban diez ayllus, agrupados en dos sayas, Hanan y Hurin. Esto implicaba que todo individuo era simultáneamente miembro de un ayllu y de una saya; finalmente, del repartimiento como unidad jurisdiccional colonial. Cada uno de los ayllus, como unidades mínimas por encima de las unidades domésticas, poseía un territorio común, un nombre, un líder o jilaqata, una organización laboral y miembros internamente diferenciados según su acceso a recursos, su paso por distintos cargos de liderazgo indígena y/o su exención fiscal.

Tras casi un siglo de dominio colonial, los integrantes del repartimiento de Macha habían transformado sus preeminencias y lazos socio-políticos internos. Reasentamiento poblacional, cambios en los patrones territoriales y en las jerarquías de liderazgo indígena, recambio de las facciones gobernantes, descenso poblacional, trabajo compulsivo en la minería potosina y demanda monetaria, acceso a la justicia colonial, migraciones internas y participación individual y colectiva en los circuitos mercantiles regionales: todos estos factores modelaron los vínculos establecidos al interior del repartimiento. Sin embargo, los procesos enumerados no lesionaron al repartimiento por igual y, tanto a nivel organizativo como con relación al acceso a los recursos, cada uno de sus ayllus y sus sayas presentaba especificidades que jerarquizaban y diferenciaban a sus integrantes.

El segundo decenio del siglo XVII implicó para el repartimiento de Macha la sucesión de una averiguación y tres revisitas entre los años 1613 y 1619 debido a denuncias, connivencias y enemistades entre corregidores y jueces de revisita que cuestionaron las sucesivas cifras tributarias obtenidas. La documentación surgida de los procesos de revisita, inspecciones llevadas adelante por los corregidores de indios $\mathrm{u}$ otros oficiales reales y solicitadas por las autoridades indígenas a causa de la disparidad entre el tributo y el descenso demográfico indígena, brinda una aproximación, aunque estática y problemática, a sus integrantes y sus modos de organización sociopolítica. Las revisitas mismas eran el resultado de una correlación de fuerzas, un espectáculo de poder que representaba la capacidad de negociación del grupo indígena más que su composición social misma, por lo que su información debe ser analizada con precaución (Guevara y Salomon 1994; Zagalsky 2009). El corregidor de Chayanta Antonio Salgado llevó adelante la revisita de 1619 al repartimiento de Macha y, si bien moderó las cifras previas, convirtió en tributarios a numerosos indios principales que pretendían exenciones en función de su parentesco con antiguos líderes del repartimiento. Este período convulsionado para los integrantes del repartimiento, quienes pleitearon, protocolizaron y exhibieron sus Informaciones de Filiación y Probanzas de méritos y servicios una y otra vez ante corregidores deseosos por aumentar los tributarios, constituye el contexto preciso de los procesos judiciales utilizados por la historiografía para analizar las casas del repartimiento de Macha y, asimismo, de los padrones de revisita inéditos que se examinan en este trabajo.

Al analizar el Padrón de revisita con el que se cobraban las tasas, presentado por los caciques gobernadores al juez revisitador en 1619, sobresale que su escribano había distinguido para cuatro de los diez ayllus del repartimiento de Macha la existencia de agrupaciones sociales que, en un número variable, contenían a las unidades censales de los ayllus Alacollana, Sulcahavi, Alapicha de Hanansaya y Guacoata de 
Hurinsaya (AGN XIII, 18-7-2). Casa fue el vocablo elegido por el oficial regio que realizó el padrón, coincidiendo, en apariencia, con las menciones presentes en la Información de Filiación y el pleito por liderazgo del mismo repartimiento de los años 1613 y 1616, analizados por la historiografía.

La síntesis empírica que se brinda a continuación proviene del análisis estadístico y demográfico de los padrones de revisita de los años 1613 y aquel presentado en 1619 , incorporados a una base de datos que cruzó información de cada uno de los integrantes del repartimiento de acuerdo con sus edades, género, estatus, pertenencia segmentaria y posesiones materiales. Esta síntesis, aspira a llamar la atención sobre la complejidad y heterogeneidad de las agrupaciones sociales denominadas casas en el repartimiento de Macha por los oficiales reales del siglo XVII, privilegiando al mismo tiempo una mirada comparativa con la documentación cualitativa ya analizada por la historiografía. Se brinda una síntesis en el Cuadro 1.

Cuadro 1: Presencia de casas en el repartimiento de Macha (1613-1619), según documentación colonial.

\begin{tabular}{|c|c|c|c|}
\hline Mitad & Ayllu & Nombre de la casa & Documentación \\
\hline \multirow{7}{*}{ Hanansaya } & \multirow{2}{*}{ Alacollana } & $\begin{array}{l}\text { Casa mayor } \\
\text { Casa segunda }\end{array}$ & $\begin{array}{l}\text { AGN, XIII, 18-7-2. "Información de } \\
\text { Filiación de don Francisco González", } \\
1613 .\end{array}$ \\
\hline & & Casa de Cepeda & $\begin{array}{l}\text { AGN, XIII, 18-7-2. "Padrón de revisita } \\
\text { del repartimiento de Macha", c. } 1619 .\end{array}$ \\
\hline & \multirow[t]{2}{*}{ Sulcahavi } & $\begin{array}{l}\text { Casa de Paria } \\
\text { Casa del Ynga Soto }\end{array}$ & $\begin{array}{l}\text { AGN, XIII, 18-7-1. "Padrón y numera- } \\
\text { ción hecha por Miguel Ruiz de Bustillo } \\
\text { al Repartimiento de Macha", 1613- } \\
1614 \text {. }\end{array}$ \\
\hline & & $\begin{array}{l}\text { Casa de Tataparia } \\
\text { Casa de Cataricayo }\end{array}$ & $\begin{array}{l}\text { AGN, XIII, 18-7-2. "Padrón de revisita } \\
\text { del repartimiento de Macha", c. } 1619 .\end{array}$ \\
\hline & Guaracoata & "Una misma casa y cepa" & $\begin{array}{l}\text { AGN, XIII, 18-7-2. "Probanza de méri- } \\
\text { tos y servicios de don Joan de Castro y } \\
\text { Paria", } 1613 \text {. }\end{array}$ \\
\hline & Taponata & 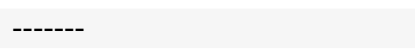 & ----- \\
\hline & Alapicha & $\begin{array}{l}\text { Casa de Chintari } \\
\text { Casa de Chara } \\
\text { Casa de Picha } \\
\text { Casa de Chuqui } \\
\text { Casa de Hayoni } \\
\text { Casa de Pomacara } \\
\text { Casa de Chacato } \\
\text { Casa de Cau }\end{array}$ & $\begin{array}{l}\text { AGN, XIII, 18-7-2. "Padrón de revisita } \\
\text { del repartimiento de Macha", c. } 1619 .\end{array}$ \\
\hline \multirow{5}{*}{ Hurinsaya } & Mahacollana & ----- & ----- \\
\hline & Sulcahata & ----- & ----- \\
\hline & Guacoata & $\begin{array}{l}\text { Primera casa de Sava } \\
\text { Segunda casa de Sayaba Tomiri }\end{array}$ & $\begin{array}{l}\text { AGN, XIII, 18-7-2. "Padrón de revisita } \\
\text { del repartimiento de Macha", c. } 1619 .\end{array}$ \\
\hline & Condoata & 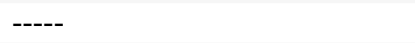 & ----- \\
\hline & Mahapicha & ----- & ----- \\
\hline
\end{tabular}




\subsection{Parcialidad Hanansaya}

La población vinculada con la parcialidad Hanansaya del repartimiento de Macha del siglo XVII se dividía de modo desigual en cinco ayllus: Alacollana, Sulcahavi, Guaracoata, Taponata y Alapicha. Hasta el momento, cuatro de ellos presentan referencias en distintos tipos de documentación colonial que indican la presencia en su interior de entidades sociales que los oficiales reales denominaron casas. Se analizó en otra oportunidad la información empírica relativa a la presencia de casas en la mitad Hanan, proveniente tanto de probanzas de méritos y servicios como de padrones de revisita del siglo XVII (Jurado 2010, 2013). A continuación, sólo se incluye una síntesis a fin de brindar una mirada comparativa con la información inédita de Hurinsaya y continuar la línea de argumentación del presente trabajo.

El ayllu Alacollana constituye el caso paradigmático del modelo segmentario para sostener la existencia de casas jerarquizadas en el repartimiento de Macha -casa mayor y casa segunda-, a partir de la lectura de la Información de Filiación del indio cantor don Francisco González [1613]. En ella, un grupo de tres testigos manifestaba la pertenencia del peticionario a un linaje de líderes de ayllu desde tiempos incaicos, explicitando que en Alacollana existían dos casas de donde provenían los líderes y que el peticionario pertenecía por «línea recta de varón» a «la casa principal de donde salen los caciques de pachacas» (AGN XIII, 18-7-2: 285r). El segundo grupo de testigos -que incluía al único perteneciente a Hanansaya- sostenía la existencia de una casa mayor y una casa segunda, con el objeto de explicar al juez la jerarquía existente entre los distintos aspirantes al cargo.

Por su parte, el padrón de revisita del repartimiento de Macha de 1613 -realizado por el mismo corregidor ante quien se dirimió la Información de filiación anteriorno registró la existencia de casas al interior del ayllu Alacollana (AGN XIII, 18-71), mientras que el padrón presentado en 1619 mencionaba la «casa de Cepeda», en referencia al nombre del jilaqata del ayllu, don Joan de Cepeda. Pese a que este ayllu poseía 324 integrantes, la «casa de Cepeda» comprendía sólo la unidad censal del jilaqata y, por entonces, líder segunda persona de todo Hanansaya. El ejemplo sugiere quizás la intencionalidad del líder indígena o del oficial real de conformar un linaje, vinculado a un cargo de autoridad indígena reconocido por el dominio colonial. Al igual que en las probanzas de méritos de importantes líderes indígenas del Surandino, como don Juan Colque Guarache [1575] o don Fernando Ayra de Arriutu [1638], antes mencionados, la casa se delimitaba en esta ocasión como aquel grupo de descendientes vinculado con una autoridad indígena.

Similar al anterior, el ayllu Guaracoata constituyó un caso empírico nodal para la definición tradicional de casa, dada la mención que se realizaba en 1616 -durante el pleito por el acceso al cargo de jilaqata - acerca de que distintos aspirantes eran «descendientes de una misma casa y sepa y primos hermanos» (AGN XIII, 18-7-2: 324r). Sin embargo, avanzado el expediente judicial, no sólo los testimonios negaban el parentesco mencionado sino que, lejos del discurso centrado en la existencia de casas, se imponía la dicotomía indio tributario / líder como la estrategia discursiva central para la obtención del cargo. Por su parte, el Padrón de revisita presentado en 
1619, no mencionaba la existencia de casas para el ayllu Guaracoata y ubicaba a los antiguos pleitistas como indios tributarios obligados a mita y tasa.

Los ayllus Sulcahavi y Alapicha de la mitad Hanansaya presentan una situación compleja. Sulcahavi fue el único ayllu del repartimiento de Macha que registró la presencia de casas tanto en el Padrón de revisita presentado en 1619 como en el confeccionado por el corregidor Miguel Ruiz de Bustillo seis años antes. En este último, el escribano registró a la totalidad de sus integrantes divididos en dos casas: la «casa de Paria» y la «casa del Ynga Soto». Para entonces, y desde la Visita General del Virrey Toledo, el cacique gobernador del repartimiento de Macha era don Pedro Soto, perteneciente al ayllu Sulcahavi. Según testimonios de la Probanza de méritos de don Joan de Castro y Paria [1612], don Pedro Soto había obtenido el cargo de manera espuria, al desplazar a los descendientes del líder Tataparia considerados «menores de edad» (AGN XIII, 18-7-2). No sorprende, entonces, que se encuentren en el registro del ayllu Sulcahavi del Padrón de revisita de 1613 dos casas que recordaban en sus nombres dos legitimidades contrapuestas: una, la de «Paria», vinculada a un líder prestigioso en la memoria colectiva de los hanansayas; y otra en torno al nombre castellano Soto - junto a una legitimidad incaica bajo la forma «Ynga Soto»-, que la ligaba a don Pedro Soto, cacique gobernador del repartimiento.

Algunos elementos del padrón indican la existencia de desigualdades entre ambas casas en 1613. A nivel demográfico, la «casa de Paria» concentraba ligeramente más población -casi el 57\% del total-, mientras que el número de tributarios era similar en ambas casas. Si bien los datos provistos por el padrón son generales, los recursos agrícolas aparecían desigualmente distribuidos, pues la «casa de Paria» controlaba el $65,2 \%$ de las fanegas de sembradura de maíz de todo el ayllu en desmedro de la de «Ynga Soto», que poseía sólo el 34,8\% para una población que representaba el 43,4\% de la población total.

Por su parte, en el Padrón de revisita presentado en 1619, el escribano agrupó a los 455 integrantes del ayllu Sulcahavi en dos casas: la de «Tataparia» y la de «Cataricayo», cada una con su líder. El cambio de nombres no se acompañaba de una transformación abrupta de las relaciones anteriores: las mismas personas se encontraban censadas en las mismas casas, indicando la continuidad entre la casa de «Paria» $\mathrm{y}$ «Tataparia», por un lado, y la de «Ynga Soto» y «Cataricayo», por el otro. Los nuevos nombres parecen evocar líderes significativos para la memoria colectiva. Distintas probanzas de méritos y servicios afirmaron que Tataparia fue «señor universal de toda la nación de los Caracaras», e incluso, «señor de los urcosuyos» en tiempos de Huayna Capac y Manco Inca (AGN XIII, 18-7-2: 298v). Por otro lado, si bien carecemos hasta el momento de información relativa a quien fuera recordado en la «casa de Cataricayo», su nombre porta reminiscencias insoslayables para el lector del mundo andino: Tomás Katari (del ayllu Mahapicha, Hurinsaya) es quien en 1780 lideraría la rebelión del repartimiento de Macha contra Joaquín Alos, corregidor de Chayanta, y contra Blas Doria Bernal, su cacique principal (Serulnikov 2006: 232). En este caso, el nombre Catari pareciera no ser una posesión inmaterial exclusiva de la casa dado que numerosos indios de ambas sayas lo utilizaron como apellido frente a la administración colonial. 
Si bien la cantidad de población agrupada en ambas casas era similar para 1619, la «casa de Tataparia» concentraba mayor cantidad de tributarios. En ninguno de los dos casos, la población comprendida en ellas tenía un mismo apellido, tampoco incorporaba el nombre de la casa en sus nombres ni existía un nombre predominante entre sus miembros. Los recursos agrícolas se distribuían proporcionalmente a la cantidad de población aunque la concentración de la producción era mayor para el caso de «Cataricayo». Por su parte, la «casa de Tataparia» se dispersaba por ocho valles, incluyendo los tres a los que concurrían los de «Cataricayo». La situación no era similar en el caso de la posesión de ganado: la «casa de Tataparia» contaba con más bueyes, vacas, alpacas y llamas, mientras que la «casa de Cataricayo» aparecía en el Padrón como una agrupación orientada al cuidado de algunas decenas de llamas.

Finalmente, según los datos contenidos en el Padrón de revisita presentado en 1619, el ayllu Alapicha también registraba la presencia de casas; sin embargo, ellas excluían a la población censada en el pueblo de reducción de Miraflores. Solamente las unidades censales de los 72 tributarios registrados en el pueblo de puna de San Pedro de Macha se agrupaban en ocho casas, cada una con su nombre distintivo, conteniendo al $60 \%$ de la población total del ayllu y controlando el $83 \%$ de las fanegas de sembradura de maíz. Según la secuencia del padrón, ellas eran: Chintari, Chara, Picha, Chuqui, Hayoni, Pomacara, Chacato y Cau. En este caso, es difícil asimilar sus nombres con los ancestros o los señores étnicos.

Las casas de Alapicha presentaban distintos planos de desigualdad. Desde el punto de vista demográfico y en relación con el control territorial, la «casa de Chintari»aquella que contenía al líder del ayllu- nucleaba la mayor cantidad de tributarios, de población y de fanegas de sembradura de maíz. En segundo lugar, la casa nombrada «Pomacara» poseía once tributarios, 41 personas y el 12\% de las fanegas de sembradura de maíz. Las de «Chuqui» y «Hayoni» eran similares en cantidad de tributarios, población y fanegas de maíz. «Chara» se ubicaba en quinto lugar; luego «Chacato», «Picha» y por último «Cau», con sólo una unidad censal compuesta por tres personas y un tributario. Todas ellas se entremezclaban en el espacio compartiendo, en diversas combinaciones, el control de determinados valles. En cuanto al ganado, solamente las casas de «Chintari», «Chuqui» y «Pomacara» poseían en total cuatro unidades censales que se inclinaban por el cuidado de alpacas; las restantes pertenecían a individuos ajenos a las agrupaciones en casas.

Las unidades censales encabezadas por individuos exentos del tributo, empadronadas bajo las categorías de viejos, viejas, impedidos, viudas y huérfanos, sumaban 175 personas y no estaban comprendidas en casas. Esa población representaba casi el $40 \%$ de los censados del ayllu Alapicha y, si bien encontramos que algunos de ellos contaban con cierta cantidad de ganado, poseían para su mantenimiento el $17 \%$ de las fanegas de sembradura de maíz de acuerdo con el padrón. Es claro que en este caso, aunque bajo el mismo nombre de casa, nos encontramos con un tipo de organización social distinta a las anteriores. Integradas por unidades censales de tributarios, todas registradas en el pueblo de reducción de puna de San Pedro de Macha, ¿es posible que estemos en presencia de una entidad social que sirviera de contención de aquellos tributarios que iban a mita, o que se ausentaban de su ayllu para obtener recursos adicionales para pagar la tasa? ¿Acaso se utilizaban para ordenar los turnos rotativos 
entre los trabajadores en el cumplimiento de las tareas tributarias, o adscribían tareas a ciertos miembros del ayllu? El ayllu Alapicha enriquece nuestros interrogantes sobre las casas aymaras y demanda futuros análisis.

\subsection{Parcialidad Hurinsaya}

A inicios del siglo XVII, la población vinculada con la parcialidad Hurinsaya del repartimiento de Macha se agrupaba de modo desigual en cinco ayllus: Mahacollana, Sulcahata, Guacoata, Condoata y Mahapicha. Si bien contamos con Informaciones de Filiación y probanzas de méritos y servicios de distintos líderes indígenas hurinsayas bajo dominio colonial, sus argumentaciones no incorporaron el término casa. Hasta el momento, el término sólo se menciona en el Padrón de revisita presentado por los líderes indígenas en 1619. De sus cinco ayllus, Guacoata constituye el único de la saya para el cual el escribano de revisita consignó la existencia de casas, y su situación presenta similitudes con aquella del ayllu Sulcahavi (Hanansaya).

Del entrecruzamiento estadístico de información relativa a sus 455 integrantes, se evidencia que estaban agrupados de manera desigual en dos casas: la «primera casa de Sava» y la «segunda casa de Sayaba Tomiri», cada una con su líder principal. Los nombres de las casas parecen evocar líderes significativos para la memoria colectiva. En efecto, el líder de la primera casa, don Diego Luis Sava, decía ser «nieto» de don Diego Sava, segunda persona de la parcialidad Hurinsaya por orden del Virrey don Francisco de Toledo. Es relevante la mención a un líder segunda persona perteneciente a la «primera casa», pues contradice lo propuesto por la historiografía acerca de que el líder principal provenía de la casa mayor mientras que la segunda persona, producto de una descendencia secundaria, pertenecía a la segunda casa (Platt et al. 2006: 663-664).

En el caso de la «segunda casa de Sayaba Tomiri», se evidencia que Tomiri es el apellido de su líder principal así como un nombre reiterado entre sus miembros. Tomiri refiere al tumi o «cuchillo de los indios» según el Vocabulario aymara de Bertonio, o, incluso a la «tierra de pan llevar» (ttumiri uraque) (Bertonio 1984 [1612]: 364). Tomiri es también uno de los nombres de quien ejerciera el cargo de segunda persona de Hurinsaya al menos desde 1612, don Gabriel Tomiri Fragoso, perteneciente al ayllu Guacoata. A partir del pleito dirimido en 1619 frente al corregidor Antonio Salgado en relación con el mencionado cargo, don Gabriel revelaba haber tenido pleitos con su «primo» don Diego Luis Sava, antigua segunda persona de los hurinsayas e integrante de la "casa de Sava», ante la Real Audiencia de Charcas, por reclamar derechos al cargo en disputa (AGN XIII, 18-7-2). En este caso, don Gabriel recordaba descender de una línea de segundas personas que se remontaba hasta el líder Tacava, quien lo fuera en tiempos de los incas (Jurado 2008). Pese a esto, la «segunda casa de Sayaba Tomiri» no recordaba en su nombre a este antepasado prehispánico sino, más bien, a aquellos líderes vinculados al dominio colonial. Se reflexiona en el siguiente apartado acerca del pleito entre las casas de «Sava» y «Sayaba Tomiri», cuyos representantes aspiraban al mismo cargo de segunda persona de Hurinsaya, esgrimiendo derechos de herencia patrilineal. 
Según la información del padrón de revisita, la «primera casa de Sava» poseía el $61,8 \%$ de la población total del ayllu y agrupaba la mayor cantidad de tributarios. Si bien eran desiguales a nivel demográfico, las dos casas mantenían un número similar de población permanente censada en el pueblo de Miraflores, indicando la importancia que revestía para sus integrantes mantener una presencia constante en los valles. En ninguno de los dos casos, la población comprendida en las casas tenía un mismo apellido ni existía un nombre que fuera predominante. Un número relativamente importante de hombres de la "segunda casa» incorporaba el nombre «Tomiri» como apellido, intercalado con otros como Catari. Se hace notar que Catari era el nombre reivindicado por la «casa de Cataricayo» del ayllu Sulcahavi; se menciona aquí pues, una vez más, los ejemplos sugieren que el nombre no era un atributo simbólico exclusivo ni excluyente de las casas del repartimiento de Macha.

Los recursos agrícolas se distribuían proporcionalmente a la cantidad de integrantes de las casas y no existían valles diferenciados para cada una de ellas. En cambio, la situación no era similar para el ganado pues los animales no estaban distribuidos equilibradamente: la «primera casa» disponía del $73 \%$ de la totalidad de las vacas y del 70\% de las alpacas, además de ser la única que poseía llamas.

En síntesis, el Padrón de revisita presentado en 1619 deja entrever la existencia de dos agrupaciones sociales al interior del ayllu Guacoata, recordando la práctica dual que se mencionó para el ayllu Sulcahavi de Hanansaya. Su jerarquización resulta evidente al constituirse en «primera casa» y «segunda casa», desigualdad confirmada por la disparidad existente en el control demográfico y de recursos ganaderos. Por último, sus nombres evocaban una legitimidad que refería a líderes de la mitad, al menos desde el Virrey Toledo hasta principios del siglo XVII.

\section{Releyendo las casas del repartimiento de Macha}

La síntesis empírica precedente llama la atención sobre cómo, para comienzos del siglo XVII, en diversa documentación colonial se utilizó el concepto de casa para describir entidades sociales al interior de ciertos ayllus de ambas mitades del repartimiento de Macha. No sólo en el Padrón de revisita y en la Información de Filiación de don Francisco González realizados ante el corregidor Ruiz de Bustillo en 1613, sino también en el pleito dirimido en 1616 y en el Padrón de revisita presentado ante Antonio Salgado en 1619, diferentes oficiales reales identificaron ciertas organizaciones indígenas con el término castellano casa. De su lectura, las casas del repartimiento de Macha se delinean como agrupaciones heterogéneas, demográficamente variables, flexibles y, aún cuando el parentesco jugara un rol central en su reproducción social, resulta claro que otras prácticas simbólicas y materiales eran centrales en su desarrollo.

En el siglo XVII, la casa como entidad social era una institución y una práctica familiares para los oficiales reales que realizaron las escrituras legales y adscribieron el nombre a lo observado, por la ineludible referencia a las casas nobiliarias europeas. En la sociedad peninsular, el individuo obtenía su identidad social en tanto miembro de un grupo parental amplio y flexible, el cual situaba a sus miembros, según el 
estatus de cada uno, en el conjunto de las relaciones sociales al mismo tiempo que sustentaba el control sobre la tierra y la mano de obra (Chacón y Hernández 1992: 7-14; Rodríguez 1992: 15-34; Pérez 1996: 53-71).

Fue precisamente el comportamiento de las casas nobiliarias europeas, y aquellas del Japón de los períodos Heian y posteriores, lo que brindó al antropólogo Claude Lévi-Strauss el modo de comprender elementos dispares y contradictorios de la compleja organización social Kwakiutl (1981: 140-162, 1996: 144-145). El modelo de sociétés à maisons que Lévi-Strauss formulara desde fines de la década de 1970, llamaba la atención sobre el rol de las prácticas sociales, más que de los lazos biológicos, en la formación de entidades sociales, aún cuando aquellas se representaran como si estuvieran fundadas en lazos de descendencia, afinidad o ambos. Numerosos investigadores tomaron su propuesta para analizar la estructura socio-política de diversas sociedades en diferentes partes del mundo y períodos históricos; entre ellas, las sociedades de la Amazonía y las mesoamericanas de los períodos Clásico y Postclásico (Beck 2007; Carsten y Hugh-Jones 1995a; Chance 2000; Combès y Villar 2004; Gillespie 2000a, 2007, 2011; Hutson et al. 2004; Joyce y Gillespie 2000; Manzanilla 2007; Sandstrom 2005; entre otros). Se propone en este trabajo que el modelo de la sociedad de casas constituye una herramienta de análisis útil para plantear nuevas preguntas acerca de las casas de la formación socio-política aymara contenida en el repartimiento de Macha del siglo XVII, al enfocar en sus aspectos políticos y materiales y en el modo en el que estas relaciones sociales fueron cambiando a lo largo del tiempo ${ }^{3}$. Para ello, se privilegia el análisis de las casas contenidas en los ayllus Sulcahavi (Hanansaya) y Guacoata (Hurinsaya) por presentar en el Padrón de revisita de 1619 una situación similar entre sí y con algunos elementos de contacto con lo declarado en los procesos judiciales analizados por la historiografía. Así, mientras el ayllu Alacollana (Hanansaya) presentaba una casa compuesta por la unidad censal del jilaqata en ejercicio, y el ayllu Alapicha (Hanansaya) registraba ocho casas que contenían las unidades censales de los tributarios del pueblo de reducción puneño, los ayllus Sulcahavi y Guacoata registraron la presencia en su interior de agrupaciones sociales duales nombradas casas por el oficial real en el mencionado padrón de revisita. Poseedoras de un nombre y de un liderazgo distintivo, las casas de ambos ayllus agrupaban a la totalidad de su población, registrando ciertos aspectos de jerarquización y de desigualdad en su acceso a los recursos.

Las casas nobiliarias de Escocia, Bretaña, Maine y Anjou, como los numaym kwakiutl, proveían para Lévi-Strauss un esquema organizador a sus respectivas sociedades, conjugando principios de parentesco aparentemente contradictorios, como la exogamia y la endogamia, la patrilinealidad y la matrilinealidad, la descendencia y la alianza, entre otros. La casa constituye una posición social, una persona moral, único sujeto detentador de derechos y obligaciones por encima de los intereses individuales pues, en sus palabras, «no son los individuos ni las familias las que actúan: son las casas» (Lévi-Strauss 1981: 149). Para Lévi-Strauss, las casas utilizan el lenguaje del

\footnotetext{
3 Las diferencias que presentan las casas del repartimiento de Macha en relación con las casas nobiliarias europeas fueron resaltadas en Jurado 2010. Privilegiando el contraste por encima de las similitudes, y con menor evidencia empírica, las conclusiones allí vertidas proponían una lectura de las casas del repartimiento de Macha que prescindía de los aportes del análisis de Lévi-Strauss y que difiere del presente trabajo.
} 
parentesco como medio de representar relaciones que se fundan, en realidad, en el acceso a la propiedad y al prestigio; por ello, en el mismo proceso de representación, el parentesco puede ser subvertido y transformado (Lévi-Strauss 1981: 150, 1996: 144145; Gillespie 2011: 44). Así se comprende la renuncia individual de ciertos indios principales del ayllu Guaracoata al pleito por el cargo de jilaqata en 1616, al declarar de manera conjunta que «(...) nosotros no queremos tratar pleito sobre la dicha razon con el dicho don Joan Gonzalez por ser, como el y nosotros todos somos, descendientes de una misma casa y sepa y primos hermanos» (AGN XIII, 18-7-2: 324r). De este modo, eran los derechos de la casa los que primaban sobre los deseos individuales de los pleitistas inmiscuidos quienes, aunque deseosos de obtener el cargo, decidían renunciar a él pues «no es justo que entre parientes [h] aya pleitos injustos». Era la defensa de la continuidad del cargo de liderazgo dentro de la casa lo que unía deseos individuales opuestos, aunque trascendiera en ello las tensiones y conflictos que eso generaba. Al igual que lo observado por Lévi-Strauss, la continuidad de la casa se servía del lenguaje del parentesco, permitiendo a los miembros de la casa ponderar su unión y beneficiar los intereses colectivos frente a la justicia colonial aún cuando los mismos integrantes negaran el parentesco folios más adelante dentro del mismo expediente. El carácter genealógico y la importancia de los lazos biológicos, entendidos en el modelo segmentario como elementos centrales en la conformación de la casa, se ve negado por sus propios miembros sin que la casa, como persona colectiva, fuera cuestionada. En ese sentido, si bien no se pone en duda el rol central del parentesco en la reproducción de la sociedad, al mismo tiempo, otros factores y prácticas adicionales se reconocen como importantes (Hutson et al. 2004: 87).

La sociedad de casas se compone de unidades o posiciones sociales vinculadas a un nombre, una sede, un rango y privilegios que existen en un número limitado y que conforman una jerarquía nobiliaria. Según Lévi-Strauss, las casas pueden llevar el nombre colectivo formado según el fundador, otras se nombran según el lugar de origen, y por último, algunas adoptan un nombre honorífico como «los grandes», «quienes reciben en primer lugar»u otros similares (Lévi-Strauss 1981: 141-145). Según la Información de Filiación de don Francisco González del ayllu Alacollana, «el dicho don Felipe Yumo hera de casa mayor y don Domingo Cuyhara de casa segunda» (AGN XIII, 18-7-2: 285v). Destaca aquí el principio dual y jerárquico que nombra las casas según su orden de precedencia: «casa mayor» y «casa segunda» en la Información de Filiación de 1613; «casa primera» y «casa segunda» en el ayllu Guacoata según el Padrón de revisita presentado en 1619. También en el repartimiento de Macha las casas recurrieron a jerarquías contenidas en los nombres de líderes fundadores de memorias colectivas, como la «casa de Tataparia» y la de «Cataricayo» en el ayllu Sulcahavi del Padrón presentado en 1619. Se ha resaltado que en las organizaciones sociales andinas el rango de cada uno de sus segmentos se relacionaba directamente con la posición que ocupaba su ancestro fundador en una jerarquía que abarcaba a sus antepasados y otras entidades sobrenaturales, anclando las diferencias sociales en un modelo histórico y cosmológico compartido (Nielsen 2007: 53; Spalding 1974: 64-69). Así, el culto a los antepasados cumplía un papel fundamental no sólo en la constitución de las identidades colectivas sino en la reproducción de estructuras políticas y en la creación de derechos sobre los recursos (Nielsen 2007: 52). 
En ese sentido, según el modelo levistraussiano, la finalidad de las casas consiste en custodiar propiedades tangibles e intangibles: las casas kwakiutl detentaban riquezas de orden espiritual -derechos exclusivos a escudos de armas, divisas y cantos-, objetos ornamentales - como máscaras, tocados, pinturas-, terrenos de caza y recolección y sitios de pesca. Lo mismo se propuso para otras sociedades (Combès y Villar 2004: 89-90; Gillespie 2008: 76-77; Hendon y Joyce 2001; Hutson et al. 2004: 88 ; entre otros). En el repartimiento de Macha, los antepasados, los nombres de ciertos líderes y las narrativas e historias asociadas a sus personas, parecen centrales en la reproducción de las casas del ayllu Sulcahavi. Elementos intangibles, acompañados con seguridad por derechos de hacer o mostrar insignias, canciones y danzas -invisibilizados en la documentación consultada- representaban el estatus, la historia y la longevidad de las casas, como posesiones inalienables y símbolos de su identidad.

Achachi es el vocablo aymara que designa en el Vocabulario de Bertonio al «abuelo o cepa de una casa o familia» y que representa también al «término o mojón de las tierras» (Bertonio 1984 [1612]: 5). Los antepasados protegían y legitimaban el control de los recursos, ligando la memoria colectiva a los aspectos materiales más tangibles. El líder que nombraba la casa de Tataparia, del ayllu Sulcahavi, se recordaba con dos sepulturas labradas en piedra (¿chullpas?), una junto a Macha y otra en las salinas de Carata (AGN XIII, 18-7-2: 308r), territorializando y cargando al paisaje de contenido social, político y simbólico (Gil 2003: 28). El acceso y la defensa del territorio usufructuado deben haber sido elementos relevantes en el accionar de las casas del repartimiento de Macha, aún cuando el Padrón de revisita presentado en 1619 no evidenciaba el control diferenciado y exclusivo a valles o estancias de pastoreo entre las diferentes casas de un mismo ayllu. En ese sentido, se señaló más arriba que los integrantes de ambas casas del ayllu Sulcahavi, así como sucedía con aquellos de las del ayllu Guacoata, labraban sus chacras en los mismos valles y pastoreaban su ganado en similares estancias. Sin embargo, las casas se enfrentaban con vehemencia por el control de cargos de liderazgo del repartimiento, disputando ante la justicia colonial sus derechos y preeminencias.

Es notorio el enfrentamiento entre las dos casas del ayllu Sulcahavi -y lo mismo sucedía en el caso de Guacoata- por el control y permanencia en cargos de autoridad de distinto nivel jerárquico en el repartimiento, cargos que no eran necesariamente distintos ni complementarios. Como sostuvieron los testigos en la Información de Filiación de don Francisco González en 1613, «en el dicho ayllo [de Alacollana] [h] ay dos casas de donde salen los principales que lo goviernan y que el dicho Curi es de la casa principal de donde salen los caciques de pachacas» (AGN XIII, 18-7-2: 285r). Lo mismo sugiere el pleito entre don Gabriel Tomiri Fragoso, integrante de la «segunda casa de Sayaba Tomiri», y don Diego Luis Sava, de la «primera casa de Sava», ambas del ayllu Guacoata, por el acceso al cargo de segunda persona de la mitad Hurinsaya. Ambos pleitistas esgrimían derechos al cargo disputado a través del lenguaje parental de sucesión hereditaria por vía masculina; y, cada uno a su turno, había logrado ejercerlo. A un nivel segmentario superior, la misma situación evidencia el pleito de don Joan de Castro y Paria perteneciente a la «casa de Tataparia» del ayllu Sulcahavi quien denunciaba a don Pedro Soto -posible integrante de la «casa del Ynga Soto»- por haber quitado el cargo de cacique gobernador del repartimiento, 
que pertenecía a su supuesto grupo parental. Todos los ejemplos mencionados coinciden en el hecho de que dos casas de un mismo ayllu se enfrentaban para dirimir su acceso a un mismo cargo de liderazgo, pudiendo sus representantes esgrimir derechos de acceso ante la justicia colonial. De hecho, los pleitos judiciales en sí mismos pueden haber servido como un medio de mantener la identidad social, el prestigio y la preeminencia de las casas, como un ritual -entre otros-capaz de afirmar sus derechos de proveer líderes al repartimiento.

Si en el modelo de la sociedad de casas estas entidades sociales se afirman en su rol de guardianas de posesiones materiales e inmateriales y derechos territoriales, el acceso y defensa de cargos pertenecientes a la jerarquía de gobierno indígena de los repartimientos coloniales constituyen prácticas centrales, generadoras de las relaciones sociales que subyacen a las casas del repartimiento de Macha del siglo XVII. En ese sentido, el rol de las casas y sus precedencias a la hora de proveer líderes para este repartimiento constituye un elemento remarcado por la historiografía desde fines de la década de 1980, aún cuando en el análisis aquí propuesto no se asuman necesariamente las restantes hipótesis. En particular, la afirmación de la existencia de $p a-$ chaqas que, a semejanza de los cabildos de la década de 1970, componían los ayllus del repartimiento de Macha, y cuyos líderes provenían de las casas en su interior, no encuentra corroboración empírica en ninguno de los padrones de revisita consultados. Así, se propone en este trabajo la posibilidad de que la mención a pachaqas en el repartimiento de Macha que se encuentra en la Información de Filiación de don Francisco González refiera a una readaptación andino colonial de la centena o unidad social decimal de reclutamiento incaico de la mano de obra para asistir a las levas de trabajo establecidas por el Tawantinsuyu. Así, el líder de pachaqa que, según dicha documentación, surgiría de la «casa mayor», podría referir, en el caso de este repartimiento norpotosino, a aquellos líderes indígenas que, ayudando a sus jilaqatas u otras autoridades, acompañaban y auxiliaban a los contingentes de trabajadores mitayos en el cumplimiento del trabajo forzado.

El acceso desigual a la propiedad y al prestigio, la interacción socio-política y económica y la competencia por el estatus, la propiedad, la mano de obra y el capital simbólico dotan a las casas de un rol dinámico en la transformación socio-política de la sociedad que conforman (Gillespie 2000b: 51). Las casas existen en la historia y hacen historia. Necesariamente, las casas surgen, pueden modificarse, ascender y descender en el rango con relación a otras, pueden dejar de existir, pueden ser hegemonizadas por otras casas, incluso, pueden metamorfosearse en otra cosa (Gillespie 2007). Se ha propuesto también que ciertas casas quizás nunca lograran institucionalizarse, o bien, que algunas de ellas buscaran alcanzar el estatus de otras (Gillespie 2011: 45). Incluso, las sociedades de casas pueden tomar la configuración social y los valores de sus vecinas. En síntesis, las casas pueden ser vistas como un proceso (Carsten y Hugh-Jones 1995b: 36). Esto permite pensar las causas por las cuales en un lapso de seis años, entre 1613 y 1619, la formación socio-política contenida en el repartimiento de Macha multiplicó en los padrones de revisita el registro de casas de sólo un ayllu a cuatro de ellos. ¿Qué observaron los oficiales reales que les recordaba la organización de casas nobiliarias europeas al interior de sólo cuatro de los diez ayllus del repartimiento? ¿Por qué se multiplicaron las agrupaciones sociales que 
reagrupaban a los integrantes dentro de los ayllus de ambas sayas? Teniendo presente la falta de evidencia empírica sobre la existencia de casas en el repartimiento de Macha anterior a fines del siglo XVI, se sugiere que el modelo de las casas nobiliarias europeas portado por los españoles pudo haber sido tan influyente en la sociedad andina colonial de los siglos XVI y XVII que ciertos segmentos e individuos de la formación socio-política aymara del repartimiento adoptaron la organización social en casas como una herramienta política, modificándola de acuerdo a sus necesidades, intereses e incluso lógicas y cosmovisiones propias. Así, en la segunda década del siglo XVII, luego del descenso demográfico, de la transformación de la jerarquía de liderazgo, de la pérdida de sus tierras más fértiles, del afán tributario de las reglamentaciones regias y, en especial, del proceso conflictivo inherente a las múltiples revisitas desarrolladas entre 1613 y 1619, ciertos ayllus del repartimiento de Macha registraron a su población dividida en casas.

Contrasta esa estrategia colectiva con los crecientes pedidos individuales de exención tributaria que pueden constatarse en la documentación desde el siglo XVI. Frente a la individuación colonial (Spalding 1974: 89-123), los integrantes de ciertos ayllus del repartimiento de Macha pudieron haber hallado en la conformación de entidades sociales como las casas cierto resguardo corporativo. Precisamente, aquellos ayllus señalados en la documentación como organizados en casas eran aquellos de donde procedían los líderes indígenas reconocidos por el dominio colonial: don Pedro Soto, cacique gobernador del repartimiento y líder de la mitad Hanansaya pertenecía al ayllu Sulcahavi -y posiblemente a la «casa de Ynga Soto»-; la segunda persona de Hanansaya, don Joan de Cepeda, pertenecía a la «casa de Cepeda» del ayllu Alacollana; por último, don Gabriel Tomiri Fragoso, segunda persona de Hurinsaya, pertenecía a la «casa de Sayaba Tomiri» del ayllu Guacoata. La casa se delinea así en el repartimiento de Macha como una entidad social que dotaba de identidad y respaldo político-económico a ciertos líderes de repartimiento.

\section{Conclusiones}

Se ha resaltado en este trabajo que la utilización de la categoría casa en la documentación referida a las entidades sociales contenidas en el repartimiento de Macha del siglo XVII es confusa y compleja. Si bien la Información de Filiación y los pleitos por el acceso al liderazgo indígena transmiten un discurso homogéneo, los padrones de revisita del mismo período histórico y para el mismo repartimiento complejizan y cuestionan parcialmente lo afirmado hasta el momento acerca de las casas de las sociedades aymaras. Asimiladas por los oficiales reales a la unidad censal de un líder indígena -como en el ayllu Alacollana-, a la agrupación social que nucleaba los tributarios censados en la puna -como en el ayllu Alapicha- o bien, a las entidades sociales duales y jerarquizadas de los ayllus Sulcahavi y Guacoata, las casas del repartimiento de Macha, según los padrones consultados, trascienden las definiciones unívocas. El concepto de casa, tal como se aplica en la documentación del siglo XVII para la región norpotosina, encapsulaba agrupaciones sociales heterogéneas, que excedían el 
parentesco como criterio único de pertenencia, y que tuvieron finalidades aparentemente disímiles, a pesar de que los oficiales reales les dieran el mismo nombre.

A fin de potenciar las preguntas en torno a la organización social aymara colonial, el análisis propuesto en este trabajo recurrió a la contrastación empírica de la documentación consultada por la historiografía con padrones de revisita inéditos del repartimiento de Macha del siglo XVII. La perspectiva contextual y comparativa elegida, junto con el análisis demográfico y estadístico de la información brindada en los padrones de revisita para cada uno de los integrantes del repartimiento, permitieron individualizar prácticas similares tras las casas de los ayllus Sulcahavi y Guacoata. $\mathrm{Su}$ interpretación a la luz del modelo heurístico de la sociedad de casas propuesto por Claude Lévi-Strauss -y enriquecido por distintos investigadores contemporáneos- sugiere que en ambos ayllus las casas, en tanto entidades sociales, políticas y económicas duales y jerarquizadas, encargadas de mantener el control sobre bienes tangibles e intangibles, tuvieron un rol central en el control de cargos pertenecientes a la jerarquía de liderazgo del repartimiento postoledano y en la provisión de sus integrantes. Una realidad históricamente dinámica, competitiva y jerarquizada, que resalta la interacción socio-económica y la competencia entre casas -y en su interiorcomo aspectos transformadores de la sociedad aymara norpotosina colonial.

\section{Referencias documentales}

AGN (Archivo General de la Nación, Buenos Aires)

Sala XIII, legajo 18-7-1: «Padrón y numeración hecha por Miguel Ruiz de Bustillo al repartimiento de Macha», 1613-1614.

Sala XIII, legajo 18-7-2: «Padrón de revisita del repartimiento de Macha», c. 1619.

Sala XIII, legajo 18-7-2: «Pleito de don Francisco González, repartimiento de Macha», 1613.

Sala XIII, legajo 18-7-2: «Probanza de méritos y servicios de don Joan de Castro y Paria, repartimiento de Macha», 1613.

Sala XIII, legajo 18-7-2: «Pleito por el acceso al cargo de jilaqata del ayllu Guaracoata, repartimiento de Macha».

Sala XIII, legajo 18-7-2: «Información de don Pedro Dueñas de Córdoba sobre la segunda persona de Hurinsaya, repartimiento de Macha».

\section{Referencias bibliográficas}

BECK, Robin (ed.)

2007 The Durable House: House Society Models in Archaeology. Carbondale: Center for Archaeological Investigations, Southern Illinois University.

BERTONIO, Ludovico

1984 Vocabulario de la lengua aymara [1612]. Cochabamba: CERES.

CARSTEN, Janet y Stephen Hugh-Jones (eds.)

1995a About the House: Lévi-Strauss and Beyond. Cambridge/Nueva York: Cambridge University Press. 
Carsten, Janet y Stephen Hugh-Jones

1995b «Introduction: About the House. Lévi-Strauss and Beyond», en About the House: Lévi-Strauss and Beyond, J. Carsten y Stephen Hugh-Jones, eds. pp. 1-46. Cambridge/Nueva York: Cambridge University Press.

Chacón Jiménez, Francisco y Juan Hernández Franco

1992 «Introducción», en Poder, familia y consanguinidad en la España del Antiguo Régimen, Francisco Chacón y Juan Hernández, eds. pp. 7-14. Barcelona: Anthropos.

CHANCE, John

2000 «The Noble House in Colonial Puebla, Mexico: Descent, Inheritance, and the Nahua Tradition». American Anthropologist 103 (3): 485-502.

Choque CANQui, Roberto

1978 «Pedro Chipana: cacique comerciante de Calamarca». Avances 1: 28-46.

1983 «El papel de los capitanes de indios de la provincia de Pacajes 'en el entero de la mita' de Potosí». Revista Andina 1 (1): 117-125.

Combès, Isabelle y Diego VILLAR

2004 «Aristocracias chané. «Casas» en el Chaco argentino y boliviano». Journal de la Société des Américanistes 90 (2): 63-102.

DíAz REMENTERÍA, Carlos

1977 El cacique en el Virreinato del Perú. Estudio histórico-jurídico. Sevilla: Universidad de Sevilla.

ESPINOZA SORIANO, Waldemar

1969 «El 'Memorial’ de Charcas: crónica inédita de 1582». Cantuta. Revista de la Universidad de Educación 4: 117-152.

1981 «El reino aymara de Quillaca-Asanaque, siglos XV y XVI». Revista del Museo Nacional de Lima 45: 175-274.

GiL García, Francisco

2003 «Manejos espaciales, construcción de paisajes y legitimación territorial: en torno al concepto de monumento». Complutum 14: 19-38.

GiLlesPie, Susan

2000a «Rethinking Ancient Maya Social Organization: Replacing «Lineage» with «House»»». American Anthropologist 102 (3): 467-484.

2000b «Lévi-Strauss. Maison and Société à Maisons», en Beyond Kinship. Social and Material Reproduction in House Societies, Rosemary Joyce y Susan Gillespie, eds., pp. 22-52. Filadelfia: University of Pennsylvania Press.

2007 «When Is a House?», en The Durable House: House Society Models in Archaeology, Robin Beck, ed., pp. 25-50. Carbondale: Center for Archaeological Investigations, Southern Illinois University.

2008 «Aspectos corporativos de la persona (personhood) y la encarnación (embodiment) entre los mayas del periodo Clásico». Estudios de Cultura Maya 31: 65-89.

2011 «El modelo de la «casa» en la estructura política maya», en El despliegue del poder entre los mayas: nuevos estudios sobre la organización política, Ana Luisa Izquierdo, ed., pp. 29-61. México: Instituto de Investigaciones Filológicas, UNAM.

Guevara Gil, Armando y Frank SALOMON

1994 «A 'Personal Visit': Colonial Political Ritual and the Making of Indians in the Andes». Colonial Latin American Review 1-2: 3-36. 
HARris, Olivia

1986 «Ecological Duality and the Role of the Center: Northern Potosí», en Andean Ecology and Civilization. An Interdisciplinary Perspective on Andean Ecological Complementarity, Shozo Masuda, Izumi Shimada y Craig Morris, eds., pp. 311335. Tokyo: University of Tokyo Press.

Hendon, Julia A. y Rosemary A. Joyce

2001 «A Flexible Corporation: Classic Period House Societies in Eastern Mesoamerica». Ponencia presentada en el 66th Annual Meeting of the Society for American Archaeology, Sesión «Corporate Groups in Prehispanic Mesoamerica: Studies in the Variety of Social Organization and Resource Mobilization». Nueva Orleans.

Hutson, Scott, Aline Magnoni y Travis Stanton

2004 «House Rules? The Practice of Social Organization in Classic-period Chunchucmil, Yucatan, Mexico». Ancient Mesoamerica 15 (1): 75-92.

Joyce, Rosemary A. y Susan GiLlesPIE (eds.)

2000 Beyond Kinship: Social and Material Reproduction in House Societies. Filadelfia: University of Pennsylvania Press.

JuRADO, María Carolina

2008 «Delineando a las «segundas personas»: autoridades étnicas desdibujadas en Charcas colonial. Un estudio de caso». Revista Andina 46: 193-210.

2010 «Una realidad compleja: casas al interior de los ayllus Hanansayas del Repartimiento de Macha, Norte de Potosí (1613-1619)». Memoria Americana 18 (1): 71-99.

2013 «(...) todos descendientes de una misma cassa y sepa’. Discursos cacicales e información censal en torno a las casas del repartimiento de Macha (Norte de Potosí), Siglo XVII», en Aportes multidisciplinarios al estudio de los colectivos étnicos Surandinos. Reflexiones sobre Qaraqara-Charka tres años después, Ana Presta, ed., pp. 373-395. La Paz-Lima: Plural Editores-IFEA.

2014 «'Descendientes de los primeros'. Las probanzas de méritos y servicios y la genealogía cacical. Audiencia de Charcas, 1574-1719». Revista de Indias 74 (261): 387-422.

LÉVI-STRAuss, Claude

1981 La vía de las máscaras. México: Siglo XXI.

1996 «Casa», en Diccionario de Etnología y Antropología, Pierre Bonte y Michael Izard, pp. 144-145.Madrid: Ediciones Akal.

MACLEOD, Murdo

1998 «Self-Promotion: The Relaciones de Meritos y Servicios and Their Historical and Political Interpretation». Colonial Latin American Historical Review 7: 25-42.

ManZanilla, Linda

2007 «Las «casas» nobles de los barrios de Teotihuacan: estructuras exclusionistas en un entorno corporativo», en Memoria 2007, pp. 453-470. México: El Colegio Nacional.

MURRA, John

1975 Formaciones económicas y políticas del mundo andino. Lima: IEP.

1978 «La correspondencia entre un «capitán de la mita» y su apoderado en Potosí». Historia y Cultura 3: 45-58. 
NiELSEN, Axel

2006 «Plazas para los antepasados: descentralización y poder corporativo en las formaciones políticas preincaicas de los Andes circumpuneños». Estudios Atacameños 31: 63-89.

2007 Celebrando con los antepasados. Arqueología del espacio público en Los Amarillos, Quebrada de Humahuaca, Jujuy, Argentina. Argentina: Mallku Ediciones.

PÉREZ, Joseph

1996 «La aristocracia castellana en el siglo XVI», en Nobleza y sociedad en la España Moderna, $\mathrm{M}^{\mathrm{a}}$ del Carmen Iglesias, coord., pp. 53-71. Oviedo: Ediciones Nobel.

PLATT, Tristan

1978 «Symétries en miroir. Le concept de yanantin chez les Macha de Bolivie». Annales. Économies, Sociétés, Civilisations 33 (5-6): 1081-1107.

1987 «Entre Ch'axwa y Muxsa. Para una historia del pensamiento político aymara», en Tres reflexiones sobre el pensamiento andino, T. Bouysse-Cassagne, O. Harris, T. Platt y V. Cereceda, eds., pp. 61.131. La Paz: HISBOL.

2009 «From the Islands's Point of View. Warfare and Transformation in an Andean Vertical Archipielago». Journal de la Société des Américanistes 95 (2): 33-70.

Platt, Tristan, Thérèse Bouysse-CAsSAGne y Olivia Harris

2006 Qaraqara-Charka. Mallku, Inka y Rey en la provincia de Charcas (siglos XV-XVII). Historia antropológica de una confederación aymara. La Paz: IFEA-Plural.

RASNAKE, Roger

1989 Autoridad y poder en los Andes. Los kuraqkuna de Yura. La Paz: HISBOL.

Recopilación de leyes de los reynos de las Indias

1973 [1681]. Madrid: Editorial Cultura Hispánica.

Rivera CUSICANQUi, Silvia

1978 «El mallku y la sociedad colonial en el siglo XVII: el caso de Jesús de Machaca». Avances 1: 7-19.

Rivera Cusicanqui, Silvia y Tristan PlatT

1978 «El impacto colonial sobre un pueblo Pakaxa: la crisis del cacicazgo en Caquingora (Urinsaya) durante el siglo XVI». Avances 1: 101-120.

RoDRÍGUEZ SÁNCHEZ, Ángel

1992 «El poder y la familia. Formas de control y de consanguinidad en la Extremadura de los tiempos modernos», en Poder, familia y consanguinidad en la España del Antiguo Régimen, Francisco Chacón Jiménez y Juan Hernández Franco, eds., pp. 15-34. Barcelona: Anthropos.

RosTwOROWsKI, María

1977 «La estratificación social y el hatun curaca en el mundo andino». Revista Histórica 1 (2): 249-286.

SAIGNES, Thierry y Carmen Beatriz LozA

1984 «Pleito entre Bartolomé Qhari, Mallku de los Lupaqa, y los Corregidores de Chucuito (1619-1643)». Historia y Cultura 56: 29-48.

SALOMON, Frank

1975 «Don Pedro de Zambiza, un varayuj del siglo XVI». Cuadernos de Historia y Arqueología 42: 285-315. 
SANDSTROM, Alan

2005 «Grupos toponímicos y organización de casas entre los nahuas del Norte de Veracruz», en Familia y parentesco en México y Mesoamérica. Unas miradas antropológicas, David Robichaux, comp., pp. 139-166. México: Iberoamericana.

\section{SERUlnikov, Sergio}

2006 Conflictos sociales e insurrección en el mundo colonial andino. El norte de Potosí en el siglo XVIII. Buenos Aires: FCE.

SPALDING, Karen

1974 De indio a campesino. Cambios en la estructura social del Perú colonial. Lima: IEP.

STERN, Steve J.

1982 Los pueblos indígenas del Perú y el desafío de la conquista española. Huamanga hasta 1640. Madrid: Alianza Editorial.

YAPITA, Juan de Dios y Denise ARnOlD

1988 «Lo humano y lo no humano en Qaqachaka: categorías aymaras de parentesco y afinidad», en Gente de carne y hueso: tramas de parentesco en los Andes, Denise Arnold, comp., pp. 199-225. La Paz: CIAS/ILCA.

ZAGALSKY, Paula

2009 «Huellas en las revisitas: tensión social e imposición colonial». Memoria Americana 17 (2): 241-279. 